\title{
Small duct sclerosing cholangitis, a case report and review of literature
}

\begin{abstract}
PSC often undiagnosed since approximately $40 \%-50 \%$ of patients with this disease are asymptomatic. Fatigue, fever, jaundice, pruritus, and vague upper abdominal discomfort are the most commonly described symptoms at the time of diagnosis. PSC involves both the intra- and extra-hepatic bile ducts in the majority of patients while an estimated $25 \%$ of patents only have isolated intra-hepatic involvement. In other reports intr-ahepatic involvement occur in only $10 \%$ of cases.
\end{abstract}

Keywords: sclerosing cholangitis, cholestasis, intrahepatic, small ducts
Volume 8 Issue 2 - 2017

Fady MWadea

Department of Gastroenterology and hepatology, Zagazig University, Egypt

\begin{abstract}
Correspondence: Fady MWadea, Assistant professor of Internal Medicine, gastroenterology and hepatology division, Faculty of medicine, Zagazig University, Egypt, Email Fadywadea78I@yahoo.com
\end{abstract}

Received: August II, 2017 | Published: December 06, 2017

\begin{abstract}
Abbreviations: PSC, primary sclerosing cholangitis; SCC, secondary sclerosing cholangitis; NSAIDS, non-steroidal antiinflammatory drugs; HAV, hepatitis a virus; HBs, hepatitis b surface antigen; HBC, hepatitis b core; ANA, anti nuclear antibody; ASMA, anti smooth muscle antibody; AMA, anti mitochondrial antibody; ERCP, endoscopic retrograde cholangiopancreatography; CBD, common bile duct; $\mathrm{AIH}$, autoimmune hepatitis; $\mathrm{UC}$, ulcerative colitis

\section{Introduction}

Primary sclerosing cholangitis (PSC) is a cholestatic liver and biliary tract disease caused by chronic inflammation of the biliary tract epithelium not attributed to any cause. This inflammation results in multifocal intra- and/or extra hepatic biliary strictures and fibrosis leading to biliary cirrhosis and malignancy development; ${ }^{1,2}$ we reported a case of cholestasis diagnosed as isolated intrahepatic sclerosing cholangitis or small duct PSC.
\end{abstract}

\section{Case presentation}

Male patient 32 years old with no history of medical diseases apart from cholecystectomy 11years ago began to complain from recurrent episodes of fatigue, upper abdominal pain, nausea, vomiting, pruritis and yellowish discoloration of skin associated with low grade fever, however, no diarrhea or bleeding per rectum is present. Patient sought medical advice and ultrasound examination was performed that revealed obstruction of common bile duct with missed stone, ERCP was performed and temporary stent was inserted for 3 month then removed, however patient remained to complain of jaundice and pruritis without improvement. No history of significant drug intake except for occasional NSAID for tooth pain. No family history of similar conditions. Examination was non-significant apart from jaundice and epigastric tenderness with no lymphadenopathy, hepatosplenomegally or neurological manifestations. Patient gave history of recurrent periods of bilirubin elevations followed by some drop of their levels in between. Initially patient's total bilirubin level was 14 and direct bilirubin was 7, alkaline phosphatase was 600 then dropped to 337 with drop of bilirubin level to $3.5 \mathrm{mg} / \mathrm{dl}$, liver enzymes were normal, $\mathrm{CBC}$ revealed leucocytosis of about 14,000 with normal levels of hemoglobin, platelets, esinophil counts as well as normal bleeding profile. Viral markers as HAV IGM, HAV IGg, HBs antigen, HBC IGM, HBC IGg, HCV antibody were all negative. ESR 1st hour 38 and 2nd hour 71, autoimmune markers as ANA, ASMA, and AMA were negative. Pelvi abdominal ultrasound shows average size liver and spleen, no ascitis and normal caliber of CBD and intrahepatic biliary radicals that was confirmed with triphisic abdominal $\mathrm{CT}$ that was also free apart from insicional postcholecystectoy hernia. Liver biopsy was asked and revealed that liver tissue shows bile stasis with dense bile pigment in distended hepatocytes. Sinusoids are patent. Portal tract shows dense sclerotic bands, inflammatory cells, cholangitis and fibrous tissue amidst bile ducts. No evidence of regeneration nodules or cirrhotic changes, viral inclusions inside hepatocytes, dysplastic or malignant changes or features of autoimmune hepatitis (AIH) or overlap syndrome (Figure 2).

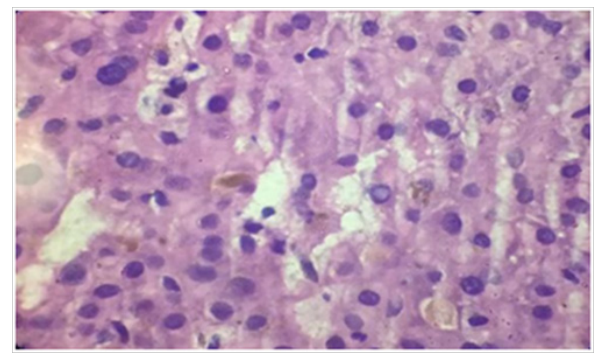

Figure I Microscopic picture for liver biopsy obtained from our patient.

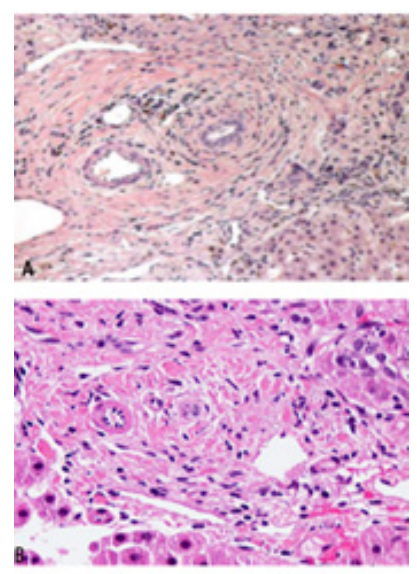

Figure 2 A. Classic 'onion skin' fibrosis, causing obliteration of the bile ducts in primary sclerosing cholangitis [Photograph courtesy: Thomas Smyrk, M.D., Department of Pathology, Mayo Clinic, Rochester].

B. Ductopenia, without onion-skinning fibrosis in small-duct primary sclerosing cholangitis [Photograph courtesy: Thomas Smyrk, M.D., Department of Pathology, Mayo Clinic, Rochester]. 


\section{Discussion}

Patients with biochemical markers and histological features suggestive of PSC with normal cholangiography findings are considered to have small-duct PSC. ${ }^{3}$ Small duct PSC may be an early stage of PSC. ${ }^{4}$ Small-duct PSC is a condition which affects only microscopic bile ducts (i.e., bile ducts seen only on liver biopsy). ${ }^{5}$ Many patients with PSC are asymptomatic with no physical abnormalities at presentation. The diagnosis is made incidentally when persistently cholestatic liver function tests are found. ${ }^{6}$ This subgroup of PSC had been less studied than the classic patients with largeduct PSC. Gallbladder wall thickening or enlargement ${ }^{7}$ gallstones, cholecystitis, and mass lesions were identified in up to $41 \%$ of patients with PSC who undergo ultrasound examinations. ${ }^{8}$ Serum aminotransferase levels are elevated in the majority of patients with this disease (about 2-3times upper limits of normal), but like the alkaline phosphatase can also be in the normal range. ${ }^{9} \mathrm{CT}$ imaging can detect thickening of the bile ducts with contrast enhancement consistent with inflammation, saccular dilatations of the intrahepatic ducts, heterogeneous bile duct dilatation, document the presence of portal hypertensive complications (i.e., varices, splenomegaly, and ascites), and can identify mass lesions. ${ }^{10-14}$ Detectable auto antibodies are found in about $97 \%$ of patients with PSC, ${ }^{15}$ these auto antibodies, however, are not routinely used for the diagnosis of PSC, as they may not be present and furthermore do not correlate with disease severity or disease prognosis. ${ }^{16}$ The classic histopathologic finding of PSC is presence of periductal concentric ("onion-skin") fibrosis, but this observation is infrequent in liver biopsy specimens from patients with PSC and may also be observed in $\mathrm{SSC}^{17}$ (Figure 1). Better prognosis in individuals with small-duct PSC was documented in many studies, however, data on this subgroup of PSC is limited due to lack of longterm follow up. ${ }^{18,19}$ A recent study for patients with small duct PSC suggested that approximately $25 \%$ of patients progress to classic PSC in an average of 8years during their follow up. ${ }^{20}$ Individuals with small-duct PSC may progress to end-stage liver disease even without developing large duct disease. Cholangiocarcinoma however, does not seem to occur in patients with small-duct disease without progression to large-duct PSC. ${ }^{20}$ The association of small-duct PSC appears to be stronger with Crohn's colitis than with UC, ${ }^{21,22}$ however as put by Jurgen Ludwig, ${ }^{23}$ the distinguished liver pathologist formerly at the Mayo Clinic, "No valid scientific reason can be found to suggest that small-duct PSC could not occur without large-duct PSC and IBD. Small-duct PSC may recur after liver transplantation. Ursodeoxycholic acid (UDCA) is widely used in the treatment of a variety of cholestatic liver diseases, but very limited data exist on its effects in small-duct PSC. ${ }^{24}$ No controlled trials of medical therapy including only patients with small-duct PSC have been performed. Patients with large-duct PSC were shown to have a better response to immunosuppressive therapy than patients with small-duct PSC. ${ }^{25}$ The better results of immunosuppressive therapy in the large-duct patients were probably linked to higher inflammatory activity indicated by the higher ALT levels in the large-duct patients as compared with the levels in the small-duct group. ${ }^{25}$ For the most part, the course of disease is milder than for large-duct disease with fewer symptoms and a favorable prognosis with regard to survival, need for transplantation is extremely small. ${ }^{26}$

\section{Conflicts of Interest}

None.

\section{Patient Consent Form}

Informed consent was taken from concerned patient.

\section{Acknowledgements}

None.

\section{Funding}

None.

\section{References}

1. Hirschfield GM, Karlsen TH, Lindor KD, et al. Primary sclerosing cholangitis. Lancet. 2013;382(9904):1587-1599.

2. Ponsioen CY, Lam K, van Milligen de Wit AW, et al. Four years experience with short term stenting in primary sclerosing cholangitis. Am J Gastroenterol. 1999;94(9):2403-2424.

3. Wee A, Ludwig J, Coffey RJ, et al. Hepatobiliary carcinoma associated with primary sclerosing cholangitis and chronic ulcerative colitis. Hum Pathol. 1985;16(7):719-726.

4. Angulo P, Maor-Kendler Y, Lindor KD. Small-duct primary sclerosing cholangitis: a long-term follow-up study. Hepatology. 2002;35(6):1494 1500 .

5. Björnsson E, Olsson R, Bergquist A, et al. The natural history of small-duct primary sclerosing cholangitis. Gastroenterology. 2008;134(4):975-980

6. Chapman R, Fevery J, Kalloo A, et al. Diseases Diagnosis and management of primary sclerosing cholangitis. Hepatology. 2010;51(2):660-678.

7. Van de Meeberg PC, Portincasa P, Wolfhagen FH, et al. Increased gall bladder volume in primary sclerosing cholangitis. Gut. 1996;39(4):594 599.

8. Said K, Glaumann H, Bergquist A. Gallbladder disease in patients with primary sclerosing cholangitis. J Hepatol. 2008;48(4):598-605.

9. Boberg KM, Fausa O, Haaland T, et al. Features of autoimmune hepatitis in primary sclerosing cholangitis: an evaluation of 114 primary sclerosing cholangitis patients according to a scoring system for the diagnosis of autoimmune hepatitis. Hepatology. 1996;23(6):1369-1376.

10. Campbell WL, Ferris JV, Holbert BL, et al. Biliary tract carcinoma complicating primary sclerosing cholangitis: evaluation with CT, cholangiography, US, and MR imaging. Radiology. 1998;207(1):41-50.

11. Ament AE, Haaga JR, Wiedenmann SD, et al. Primary sclerosing cholangitis: CT findings. J Comput Assist Tomogr. 1983;7(5):795-800.

12. Campbell WL, Peterson MS, Federle MP, et al. Using CT and cholangiography to diagnose biliary tract carcinoma complicating primary sclerosing cholangitis. AJR Am JRoentgenol. 2001;177(5):10951100 .

13. Dodd GD 3rd, Baron RL, Oliver JH 3rd, et al. End-stage primary sclerosing cholangitis: CT findings of hepatic morphology in 36 patients. Radiology. 1999;211(2):357-362.

14. Johnson KJ, Olliff JF, Olliff SP. The presence and significance of lymphadenopathy detected by $\mathrm{CT}$ in primary sclerosing cholangitis. $\mathrm{Br}$ J Radiol. 1998;71(852):1279-1282.

15. Angulo P, Peter JB, Gershwin ME, et al. Serum autoantibodies in patients with primary sclerosing cholangitis. $J$ Hepatol. 2000;32(2):182-187.

16. Gidwaney NG, Pawa S, Das KM. Pathogenesis and clinical spectrum of primary sclerosing cholangitis. World $J$ Gastroenterol. 2017;23(14):2459-2469.

17. Burak KW, Angulo P, Lindor KD. Is there a role for liver biopsy in primary sclerosing cholangitis? Am J Gastroenterol. 2003;98(5):11551158 . 
18. Björnsson E, Boberg KM, Cullen S, et al. Patients with small duct primary sclerosing cholangitis have a favorable long term prognosis. Gut. 2002;51(5):731-735.

19. Angulo P, Maor-Kendler Y, Lindor KD. Small-duct primary sclerosing cholangitis: a long-term follow-up study. Hepatolog. 2002;35(6):1494 1500 .

20. Björnsson E, Olsson R, Bergquist A, et al. The natural history of small duct primary sclerosing cholangitis. Gastroenterology. 2008;134(4):975-980.

21. Halliday JS, Djordjevic J, Lust M, et al. A unique clinical phenotype of primary sclerosing cholangitis associated with Crohn's disease. $J$ Crohns Colitis. 2012;6(2):174-181.

22. Björnsson E. Small-duct primary sclerosing cholangitis. Curr Gastroenterol Rep. 2009;11(1):37-41.
23. Ludwig J. Small-duct primary sclerosing cholangitis. Semin Liver Dis. 1991;11(1):11-17.

24. Lindor KD, Dickson ER, Baldus WP, et al. Ursodeoxycholic acid in the treatment of primary biliary cirrhosis. Gastroenterology. 1994;106(5):1284-1290.

25. Olsson R, Glaumann H, Almer S, et al. High prevalence of small duct primary sclerosing cholangitis among patients with overlapping autoimmune hepatitis and primary sclerosing cholangitis. Eur J Int Med. 2009;20(2):190-196.

26. Chapman RW. Primary sclerosing cholangitis. Medicine. 2011;39(10):588-591. 